\title{
A FIELD MEASUREMENT SYSTEM FOR WIND ENGINEERING AND ANALYSIS OF TYPHOON CHARACTERISTICS BY ULTRASONIC ANEMOMETERS
}

\author{
Xu Wang*, Huaqiang Li*, Zeng-shun Chen,***, Hua-ming Dong*, and Yangjian Xiao*
}

\begin{abstract}
A low-rise building and a tower were constructed near Shanghai Pudong International Airport by East China Sea to investigate characteristics of wind field and wind pressure on the surface of the roof. This paper firstly introduces the overview of the field measurement system and then presents the field measurement results of near-ground wind characteristics over a typical flat area near the Yangtze River estuary during typhoon HAIKUI. Variations of the wind characteristic parameters, such as mean wind speed, longitudinal turbulence intensity, gust factor and turbulence integral scale, along the height are analysed. It is found that the neutral atmospheric stratification $(|z / L| \leq 0.1)$ occurred in the periods corresponding to the relatively high mean wind speed, and $z / L$ has greater dispersion when the wind speed is relatively low. The dispersion of friction velocity is large when wind speed is small, and its variation with the mean wind speed is not obvious, but when the mean wind speed is larger, the friction velocity increases significantly with the mean wind speed. The measured mean wind speed profile is in good agreement with power and logarithmic law. Besides, the profiles of turbulence intensity, gust factor and turbulence integral scale factor are presented and empirical expressions are given by fitting the profile curve, which is useful for wind-resistant design of engineering structures in the future.
\end{abstract}

\section{Key Words}

Typhoon measurement; wind profile; turbulence intensity; gust factor; turbulence integrate scale

\footnotetext{
* State Key Laboratory Breeding Base of Mountain Bridge and Tunnel Engineering, Chongqing Jiaotong University, Chongqing 400074, People's Republic of China; e-mail: xuwang@cqjtu.edu.cn, \{lhq163youxiang, chenzs2007, Dhm0215\}@163.com,xiao@nmsu.edu

** Department of Civil and Environmental Engineering, The Hong Kong University of Science and Technology, Hong Kong, People's Republic of China

Corresponding author: Zeng-shun Chen
}

Recommended by Prof. Chaomin Luo

(DOI: 10.2316/Journal.206.2018.3.206-5087)

\section{Introduction}

Typhoon has the characteristics of sudden strong and great damage, and is one of the worst natural disasters in the world. The coastal areas of eastern China are very important in China due to the large population and developed economy but these areas are frequently hit by typhoon. Every year, the landfalls of typhoon in these areas cause tremendous deaths and injuries and also severe damage to the national economy. To reduce the huge losses of economy and casualties caused by typhoon, the characteristics of wind load produced by typhoon need to be investigated in detail.

The field measurement of near-ground wind characteristics is one of the hot research topics in wind engineering, which is useful for calibrating standards of building design and also providing valuable information for the inflow simulation of wind tunnel test. Although this research starts late in China, it is developing rapidly and many achievements have been created $([1]-[5])$. But so far, there is a severe shortage of the field measurements of near-ground profiles of wind characteristic parameters during typhoon due to the limitations of field measurement conditions.

Field measurements conducted by $\mathrm{Fu}$ et al. [6] investigated the boundary layer wind characteristics over typical open country and urban terrains. The field data such as wind speed and wind direction were continuously recorded from the observation tower and the two super-tall buildings during the passage of Tropical Storm Sanvu. The ground roughness, mean wind speed and direction, turbulence intensity, gust factor, turbulence integral length scale and spectra of wind speed fluctuations were analysed. It was found that the measurement results from the observation tower and the CPT tower indicated that the longitudinal gust factor values gradually decreased with increase in the mean wind speed, and the von Karman spectra models were identified to describe the energy distribution fairly well for the wind speed components in the longitudinal, lateral and vertical direction. Li et al. [7] investigated the vertical distributions of mean wind speed and atmospheric turbulence characteristics over a typical 


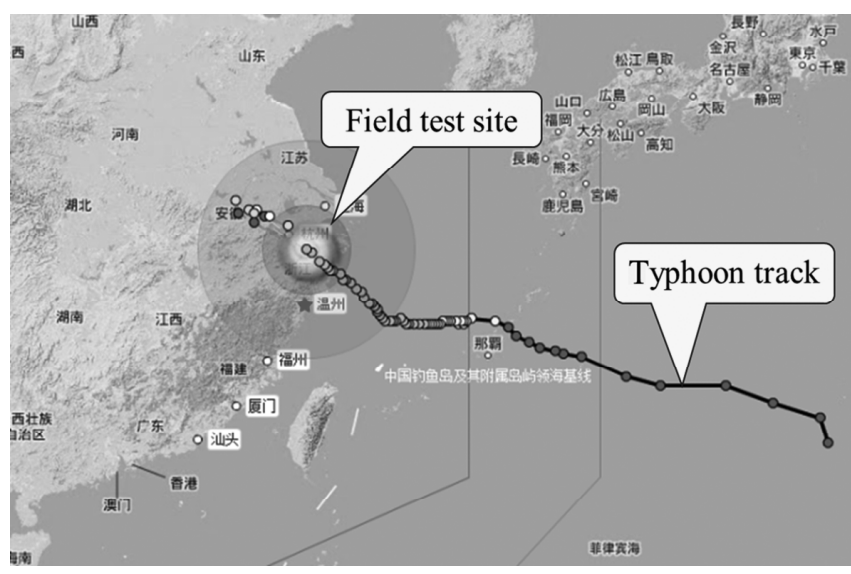

(a)

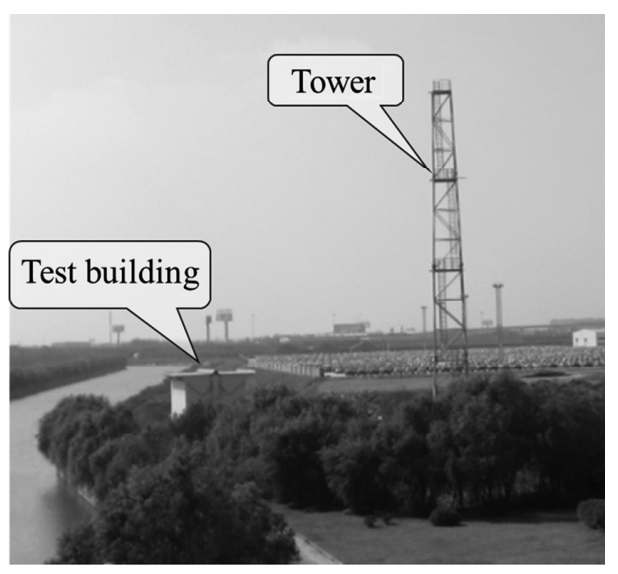

(b)

Figure 1. Moving track of typhoon HAIKUI (a) and the photo of the observation tower (b).

urban area. The wind data were measured from more than 30 anemometers installed on the $325 \mathrm{~m}$ high Beijing Meteorological Tower during numerous wind storms. Profiles of mean wind speed are presented based on the field measurements and are compared with empirical models' predictions. Besides, turbulence intensity, gust factor, turbulence integral length scale and power spectral densities of the three-dimensional fluctuating wind velocity are presented and used to evaluate the adequacy of the existing theoretical and empirical models. The research shows that the measured wind speed profiles demonstrate variations in the mean wind speed. The profiles above $100 \mathrm{~m}$ under low wind speed conditions show a more remarkable tendency to deviate from the log-law profile. In 2005 and 2006, the wind data of four typhoons were recorded by sonic anemometers at four observation sites in Guangdong and Hainan provinces [8]. Characteristics of the gust factor and the turbulence integral scale of four typhoons were analysed and the relationships among the gust factor, gust duration time, mean wind speed, roughness length and turbulence intensity were described. The turbulence integral scale was found to be closely related to the segment length and turbulence intensity. Huang et al. [9] investigated mean wind speed and direction, wind speed profiles, turbulence intensities, gust factors and peak factors on the east coast of Shanghai during typhoon Muifa. The data are recorded by eight anemometers, which were mounted on a $40 \mathrm{~m}$ tower. It is found that the measured mean wind speed profile agrees well with power-law and log-law models under $40 \mathrm{~m}$ height. Besides, the profiles of turbulence intensity and gust factors and the variations of gust factors with gust averaging time are analysed and the related empirical fitting formulas are also given. Also, many other studies [10]-[12] have focused on wind profiles and characteristics of typhoon based on filed measurements or numerical simulations. The studies mentioned above can provide useful information on the boundary layer wind characteristics for the wind-resistant design of tall buildings and high-rise structures. However, the typhoon characteristics have not been fully understood.

In some cases, field measurement is more effective to reflect the condition of the real case [13], [14], and field measurement on wind characteristics is not exceptional. In this study, the measured data of wind speed were obtained from the installed anemometers on the lattice tower in the field test site during typhoon HAIKUI. The mean wind speed and wind direction, turbulence intensities, gust factors, turbulence integral scale, etc. are analysed. Besides, wind speed profile, turbulence intensity profiles and turbulence integral length scale profiles are compared with the results from the design load code of China and other well-known wind codes.

\section{Field Measurements}

\subsection{Description of Typhoon HAIKUI}

Figure 1(a) shows the moving track of typhoon HAIKUI. On August 1, 2012, a tropical depression was born at the southeast sea of Iwo Jima, and then it developed to a tropical storm at the southeast Pacific Ocean of Okinawa County on August 3 and was named Haikui. On August 5, it moved to the East China Sea and evolved to a severe tropical storm. Afterwards, it upgraded to a typhoon on August 6 and enhanced as a severe typhoon on August 7. Finally, the typhoon Haikui landed at Xiangshan County, Zhejiang Province with the wind scale at the bottom centre exceeding 14 at 3:00 a.m. on August 8. The maximum $10 \mathrm{~min}$ mean wind speed at $10 \mathrm{~m}$ height was found to be $28 \mathrm{~m} / \mathrm{s}$, and the lowest pressure was $980 \mathrm{hPa}$. Figure 1(a) also shows the position of the field test site, and Fig. 1(b) shows the photo of tower in this site. During typhoon HAIKUI, force 10-12 wind was normally appeared on the inland of Ningbo, and force 12-14 wind existed on the coastland. The wind up to force 10 lasted $42 \mathrm{~h}$, and the $\max$ wind speed is $50.9 \mathrm{~m} / \mathrm{s}$ tested in Shipu Town.

\subsection{Experimental Instruments and Facilities}

Pudong district in Shanghai is the area where strong wind especially strong typhoons frequently occur each year. So, the laboratory for field measurement had been set up by State Key Laboratory of Disaster Reduction in Civil Engineering of Tongji University for the study of turbulence 


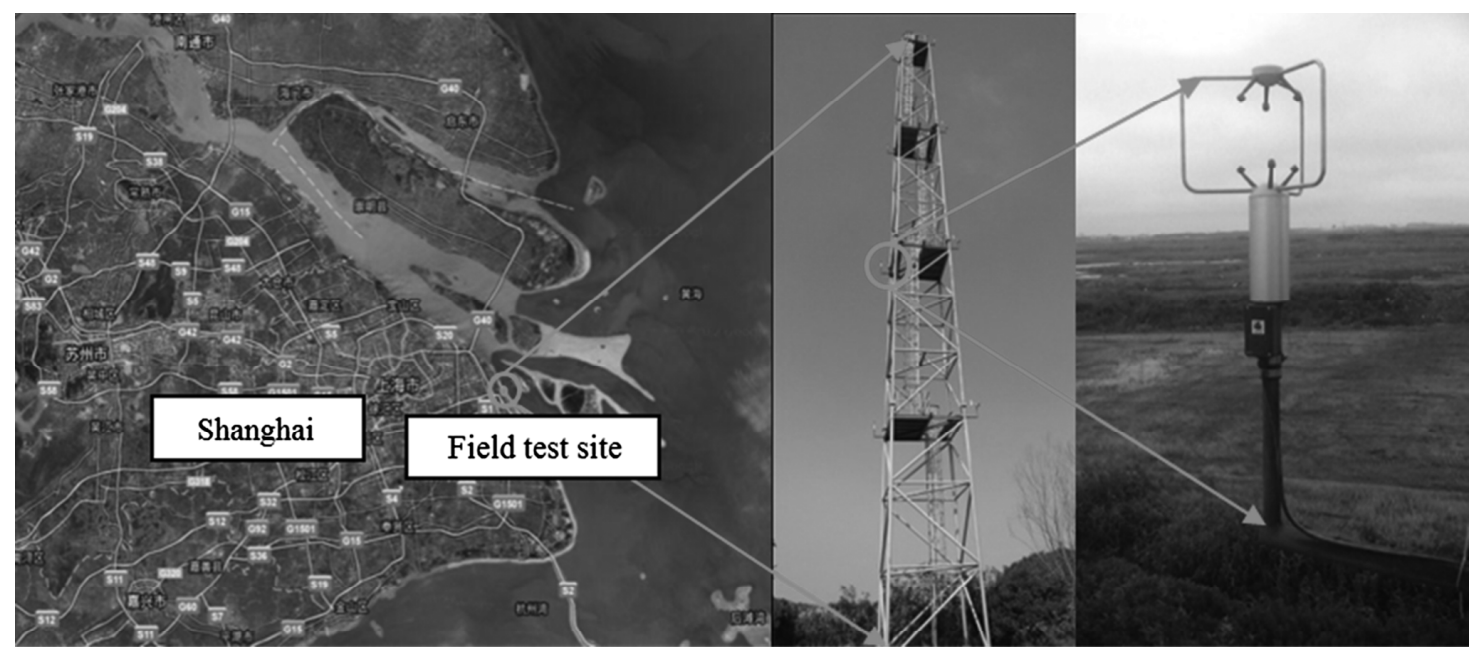

Figure 2. Position of the field test site and photos of the tower and three-dimensional ultrasonic anemometers.

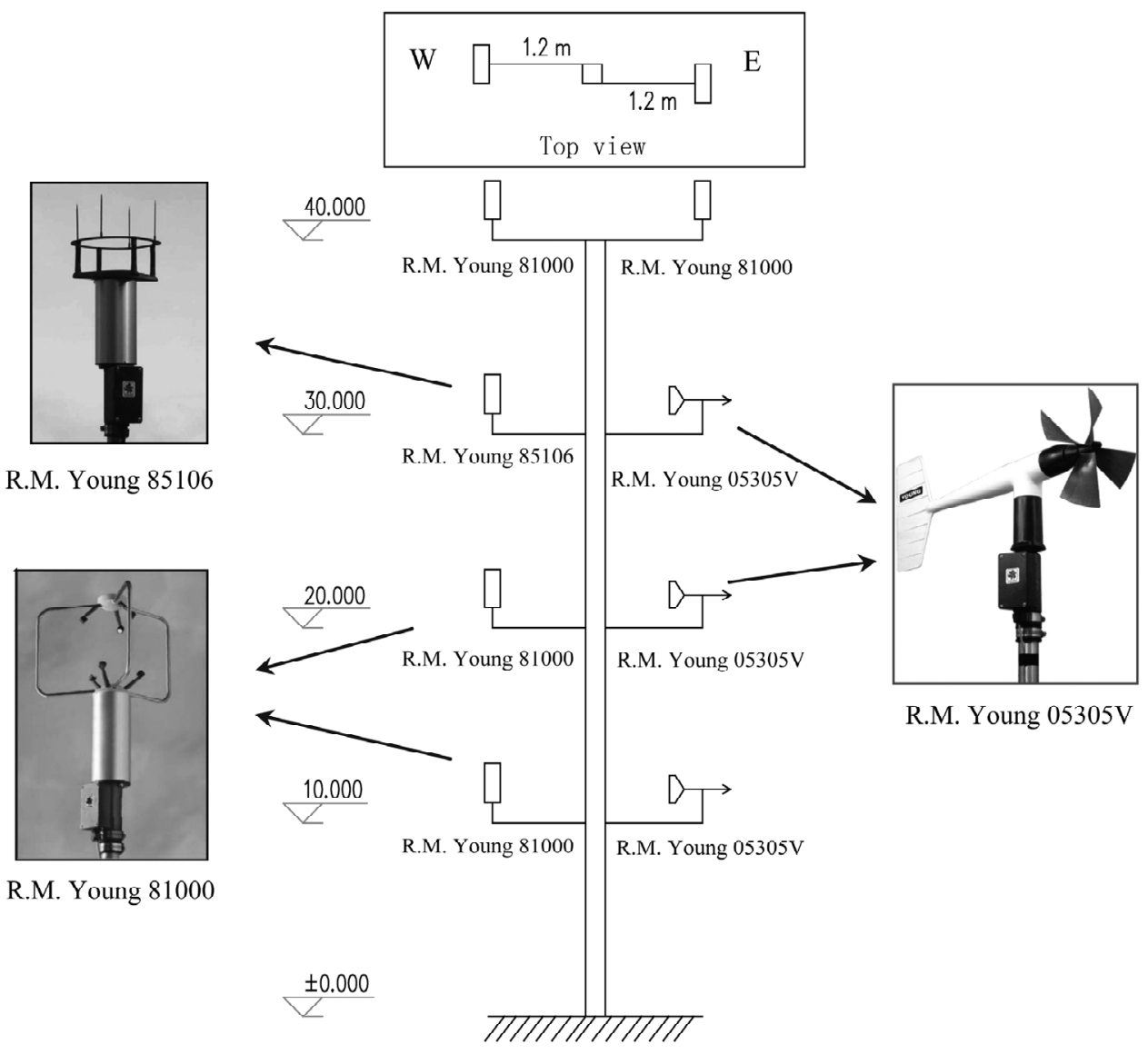

Figure 3. The arrangements of anemometers.

characteristics near ground and wind effects on low-rise buildings in the field. The field laboratory is located on flat area close to the Yangtze River estuary, and in the vicinity of Shanghai Pudong International Airport. It consists of a test building and a meteorological tower.

A lattice tower was built in this site, whose height is $40 \mathrm{~m}$. Figure 2 shows the position of the field test site and the photos of the tower and three-dimensional ultrasonic anemometers installed on this tower. Four anemometers were installed on this tower to record the wind speed and wind directions, and the heights of these anemometers are 10, 20, 30, and 40 (see Fig. 3). The distance between the anemometer and the tower body was far enough to avoid the influence of tower body on the data acquisition. Three types of anemometers were used: three-dimensional sonic anemometers (R.M. Young 81000), two-dimensional sonic anemometers (R.M. Young $85106)$ and propeller anemometers (R.M. Young 05305V). 
The wind direction of $\theta=0^{\circ}$ corresponds to the north, and the positive wind directions were defined by the clockwise rotation. The analysis in this paper is based on the data from the three-dimensional sonic anemometers because these anemometers can record the wind-speed fluctuations in three dimensions. The data from the other types of anemometers were used only to supplement and correct the results.

\section{Wind Characteristics}

\subsection{Wind Speed Profile Models}

(1) Logarithmic law

According to the asymptotic similarity considerations for a neutral atmospheric boundary layer, a wind speed profile can be expressed as [15], [16]

$$
U(z)=\frac{U_{0}^{*}}{k}\left[\ln \left(\frac{z}{z_{0}}\right)+\psi_{m}\left(\frac{z}{L}\right)\right]
$$

where $z$ is the height above the surface; $z_{0}$, the roughness length, is a measure of the roughness of the ground surface; $U(z)$ is the mean wind speed at the height $z$; $U_{0}^{*}$ is the surface friction velocity; $k$ is von Karman's constant, and has been found experimentally to have a value of about $0.4 ; L$ is the Monin-Obukhov length; $\psi_{m}$ is an universal function. When $z / L$ is zero, (1) can be simplified to the following equation:

$$
U(z)=\frac{U_{0}^{*}}{k} \ln \left(z / z_{0}\right)
$$

Friction velocity for airflow can be written in the general form as follows:

$$
U_{0}^{*}=\left({\overline{u^{\prime} w^{\prime}}}^{2}+{\overline{v^{\prime} w^{\prime}}}^{2}\right)^{1 / 4}
$$

where $u^{\prime}, v^{\prime}$ and $w^{\prime}$ are the fluctuating components in the $x, y$ and $z$ directions, respectively.

(2) Power law

The power law has no theoretical basis but has been widely used in wind engineering to describe the mean wind speed profile because of its simplicity [15]. It can be calculated by the following equation:

$$
\frac{U(z)}{U\left(z_{r e f}\right)}=\left(\frac{z}{z_{r e f}}\right)^{\alpha}
$$

where $Z_{\text {ref }}$ is the reference height, usually taken to be $10 \mathrm{~m}$ and $\alpha$ is the ground roughness exponent.

\subsection{Turbulence Intensity}

The turbulence intensity is an important parameter to determine the wind-induced dynamic response of structures. The turbulence intensities in longitudinal, lateral and vertical directions are defined as the ratios of the standard deviations of speed components to the longitudinal, lateral and vertical mean wind speeds of 10-min time series, respectively. The calculating equations are as follows:

$$
I_{u}=\frac{\sigma_{u}}{U}, \quad I_{v}=\frac{\sigma_{v}}{U}, \quad I_{w}=\frac{\sigma_{w}}{U}
$$

where $\sigma_{u}, \sigma_{v}$ and $\sigma_{w}$ are the root mean square values of the fluctuating wind speed components in longitudinal, lateral and vertical direction, respectively.

\subsection{Gust Factor}

The gust factor is another important parameter to describe the intensity of fluctuating components of wind speed. The gust factor is defined as the ratio of the gust speed within gust duration $t_{g}$ to the mean wind speed $U$ in an elementary time interval. It is expressed as

$$
\begin{aligned}
G_{u}\left(t_{g}\right) & =1+\frac{\max \left(\overline{u\left(t_{g}\right)}\right)}{U}, \quad G_{v}\left(t_{g}\right)=1+\frac{\max \left(\overline{v\left(t_{g}\right)}\right)}{U}, \\
G_{w}\left(t_{g}\right) & =1+\frac{\max \left(\overline{w\left(t_{g}\right)}\right)}{U}
\end{aligned}
$$

where $\max \left(\overline{u\left(t_{g}\right)}\right), \max \left(\overline{v\left(t_{g}\right)}\right)$ and $\max \left(\overline{w\left(t_{g}\right)}\right)$ are the maximum mean wind speed in the period of $t_{g}$ for longitudinal $(u)$, lateral $(v)$ and vertical $(w)$ fluctuations, respectively.

\subsection{Turbulence Integral Scale}

The turbulence integral scale is a measure of the average size of the turbulent eddy of flow and it varies greatly in the atmospheric boundary layer. Several methods were provided to calculate the turbulence integral scale in previous studies, but they provided significantly different calculation results [17]-[21]. The calculation method used in this paper is as follows:

$$
L_{i}^{x}=\frac{1}{\sigma_{i}^{2}} \int_{0}^{\infty} R_{i_{1} i_{2}}(x) d \mathrm{x}, \quad i=u, v, w
$$

where $\sigma_{i}^{2}$ is the variance of the wind component fluctuation and $R_{i_{1} i_{2}}(x)$ is the covariance function between the fluctuating velocity at two positions $i_{1}$ and $i_{2}$.

\section{Results and Discussions}

\subsection{Wind Speed and Wind Directions}

According to the regulations of the Chinese load code for the design of building structures [22], the whole time-series sample of wind speed was partitioned into 10-min timeseries samples to analyse the variation of the 10-min mean wind speed and wind direction during typhoon. Figures 3 and 4 show variations of 10 -min mean wind speed and 10-min mean wind direction at heights of $Z=10,20,30$ and $40 \mathrm{~m}$ during typhoon HAIKUI. In Fig. 4 , it is found that the 10-min mean wind speed shows a peak at various heights during typhoon HAIKUI, and the 10-min mean 


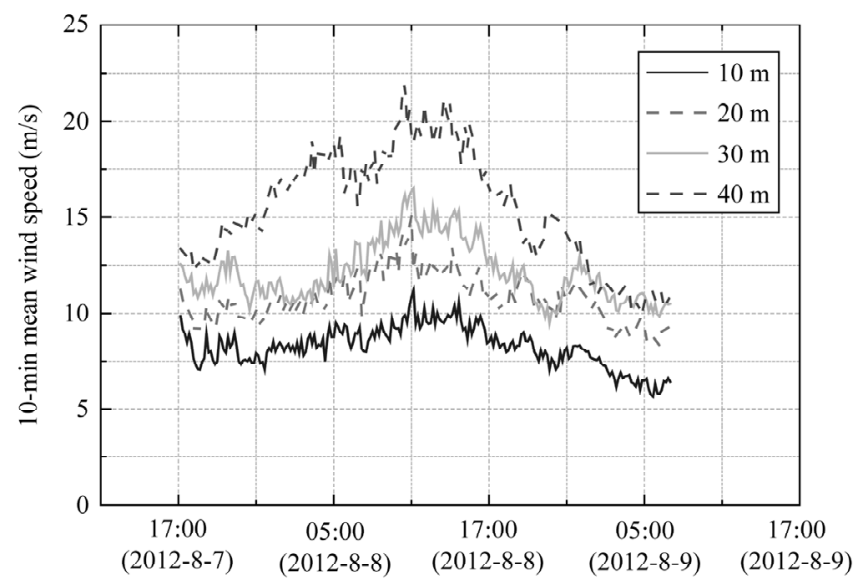

Figure 4. 10-min mean wind speed versus time.

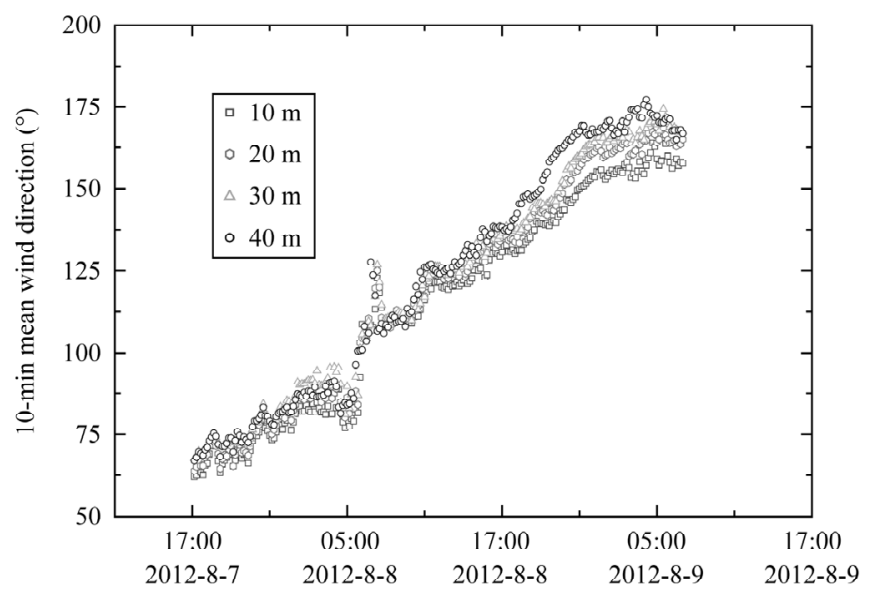

Figure 5. 10-min mean wind direction versus time.

wind speed shows an increasing trend with increasing the height. The max 10-min mean wind speed at $40 \mathrm{~m}$ is 21.89 m/s at the time of about 10 o'clock on August 8, 2012. In Fig. 5, it is found that the 10-min mean wind directions are all between $60^{\circ}$ and $180^{\circ}$, and the 10-min mean wind direction almost linearly increases with the time due to anticlockwise rotation of typhoon.

\subsection{Near-Ground Wind Characteristics}

(1) Atmospheric stability

$z / L$ is the ratio of the height with the Monin-Obukhov length, which is used to determine the stability of the atmospheric stratification. The calculation method used in this paper is as follows:

$$
z / L=-\frac{(g / T)(\overline{w T})}{\left(U_{0}^{*}\right)^{3} /(k z)}
$$

where $g$ is the acceleration of gravity, $T$ is the thermodynamic temperature and $\overline{w T}$ is the thermal flux.

Figure 6 presents the variations of $z / L$ with the mean wind speed at various heights. It is found that the neutral stratification $(|z / L| \leq 0.1)$ was occurred under the condition of high wind speed, and the values of $z / L$ are dispersed under the condition of low wind speed. Moreover, when the mean wind speed is larger than a certain value, the values of $z / L$ slightly vary with the mean wind speed, and tends to be stable at $z / L=0$. Consequently, it can be considered that the atmospheric stratification tends to be neutral under the condition of high wind speed. We can say that log law is complied with field measurement when wind speed is high enough.

\section{(2) Friction velocity}

Figure 7 presents the variation of the friction velocity with mean wind speed at various heights, and the friction velocity is calculated by (3). It is found that variation tendencies of friction velocities with the mean wind speed are similar at three heights. The dispersion of friction velocities is large under the condition of the low height $(Z=10 \mathrm{~m})$. However, when the height is larger, it can be found that the friction velocity obviously increases with the mean wind velocity, which is similar to the results by Li et al. [7]. Besides, the mean friction velocities calculated by the data at heights of $Z=10,20$ and $30 \mathrm{~m}$ are 1.23 , 1.19 and $0.83 \mathrm{~m} / \mathrm{s}$, respectively, which indicates that the mean friction velocity decreases with increasing the height. And the mean friction velocities obtained will be used to the analysis of wind speed profiles by logarithmic law.

(3) Roughness index

The power velocity profiles were adopted by Chinese load code for the design of building structures to describe the mean wind speed profile in the atmospheric boundary layer [22]. The geomorphologies were divided into four types according to the terrain roughness which is an important parameter for the wind-resistant design of structures. The geomorphic types A, B, C and $\mathrm{D}$ correspond to the roughness indexes of $\alpha=0.12$, $0.15,0.22$ and 0.3 , respectively. Figure 8 presents the variation of the measured roughness index with the mean wind speed, and the measured roughness indexes are obtained by fitting the mean wind speed at heights of $Z=10,20,30$ and $40 \mathrm{~m}$ in the form of power law. It is found that the roughness index shows a decreasing trend with increasing the mean wind speed. However, it is noteworthy that the measured mean roughness index is larger than 0.3 due to the influence of the complicated surroundings around the field test site.

(4) Wind speed profiles

The variation of mean wind speed with height near the ground is an important issue which has attracted much attention in wind engineering. Figure 9 presents the mean wind speed profiles for various periods corresponding to various mean wind speed during typhoon. It is found that the mean wind profile, the maximum wind profile and the wind profiles corresponding to various periods during typhoon are different, which means that the wind profiles are not constant during typhoon HAIKUI. 


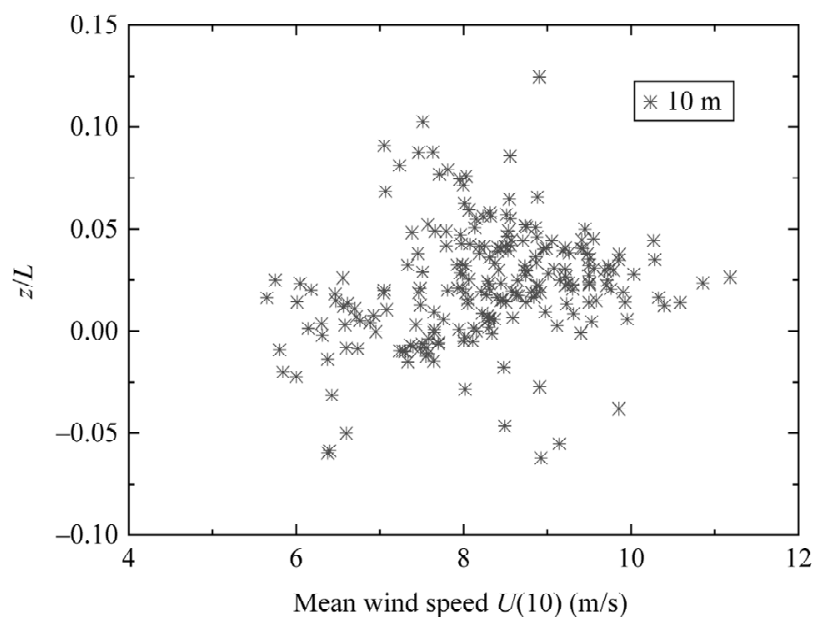

(a)

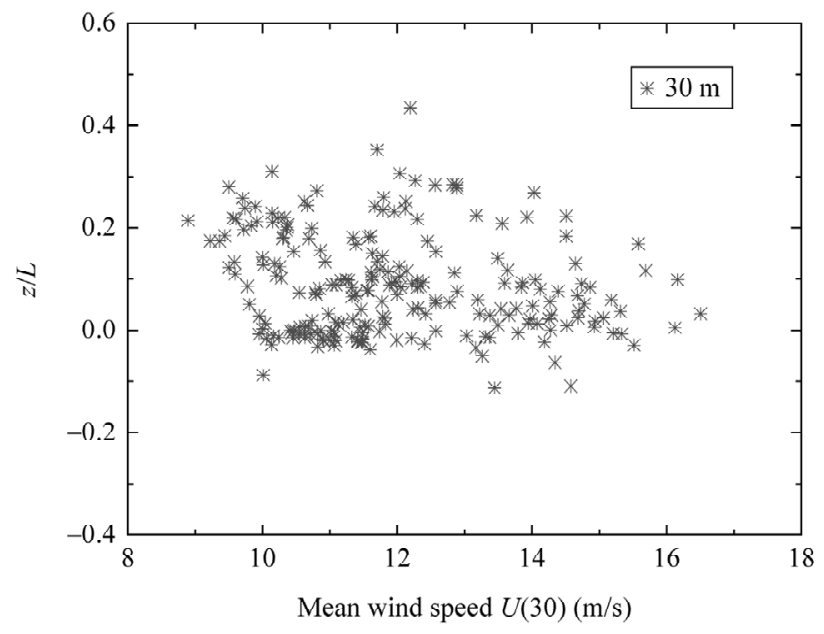

(c)

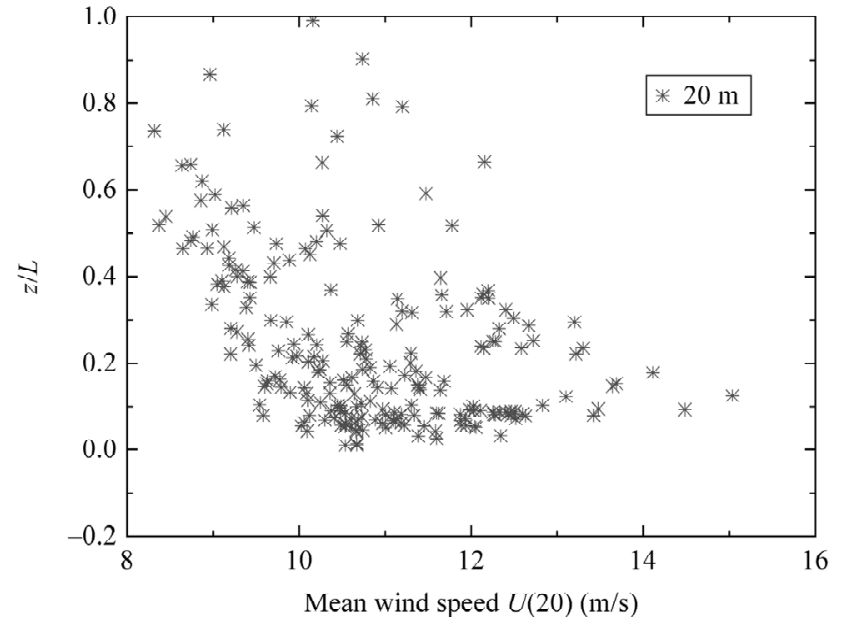

(b)

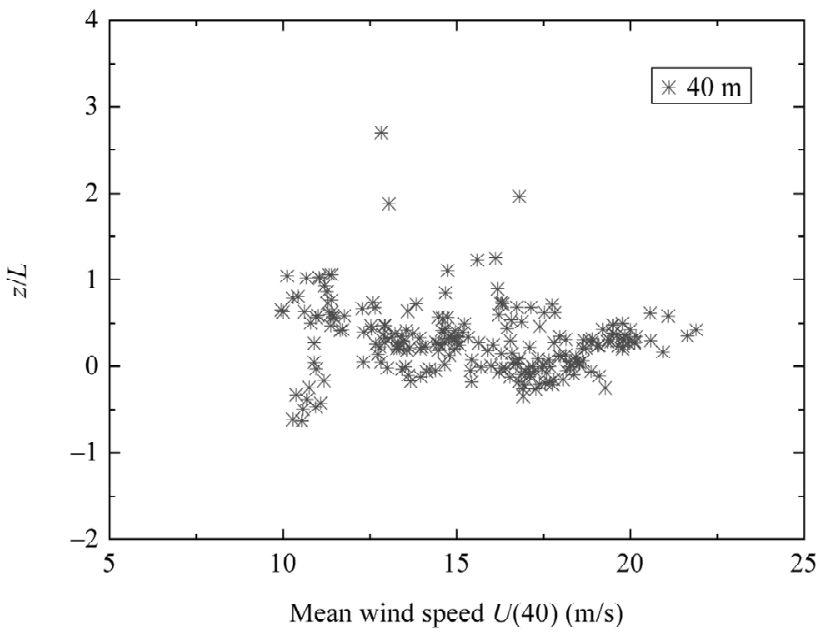

(d)

Figure 6. Variation of the atmospheric stability $z / L$ with the mean wind speed: (a) $10 \mathrm{~m}$; (b) $20 \mathrm{~m}$; (c) $30 \mathrm{~m}$; and (d) $40 \mathrm{~m}$.

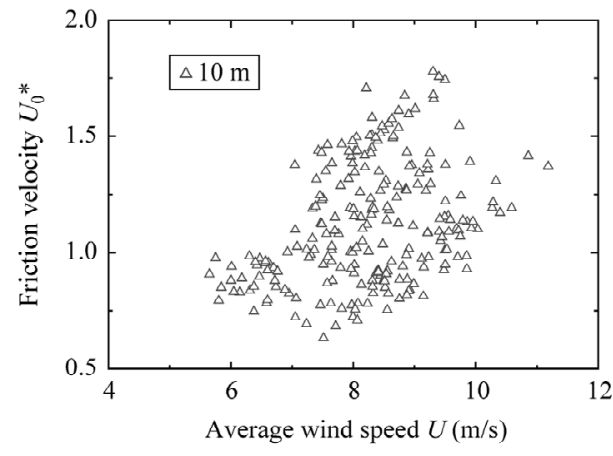

(a)

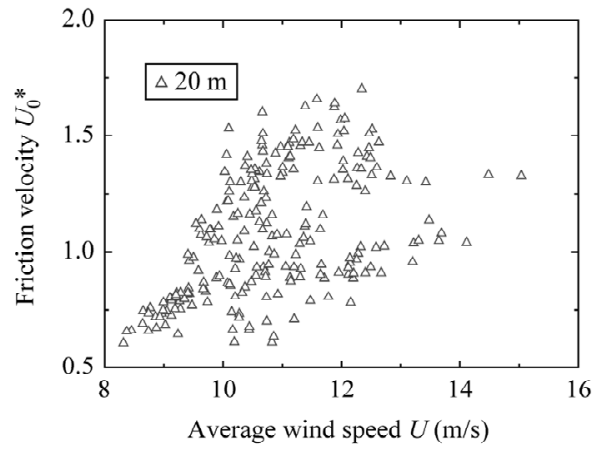

(b)

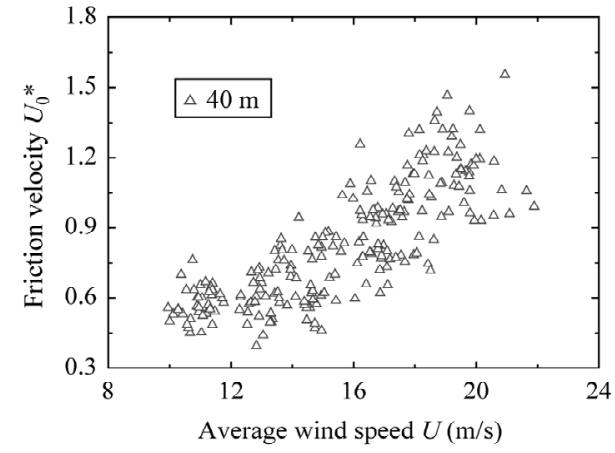

(c)

Figure 7. Variation of the friction velocity with mean wind speed at various heights: (a) $10 \mathrm{~m}$; (b) $20 \mathrm{~m}$; and (c) $40 \mathrm{~m}$.

To compare the measured wind profiles with the empirical profiles, Fig. 10 presents the mean wind profiles calculated by the periods corresponding to the mean wind speed larger than $8 \mathrm{~m} / \mathrm{s}$ and smaller than $8 \mathrm{~m} / \mathrm{s}$. Besides, empirical profiles of power and logarithmic law by fitting the measured data are also given in Fig. 10. It is found that the power and logarithmic velocity profiles are in good agreement with the measured velocity profiles, which is consistent with the results from typhoon Meifa [23]. 


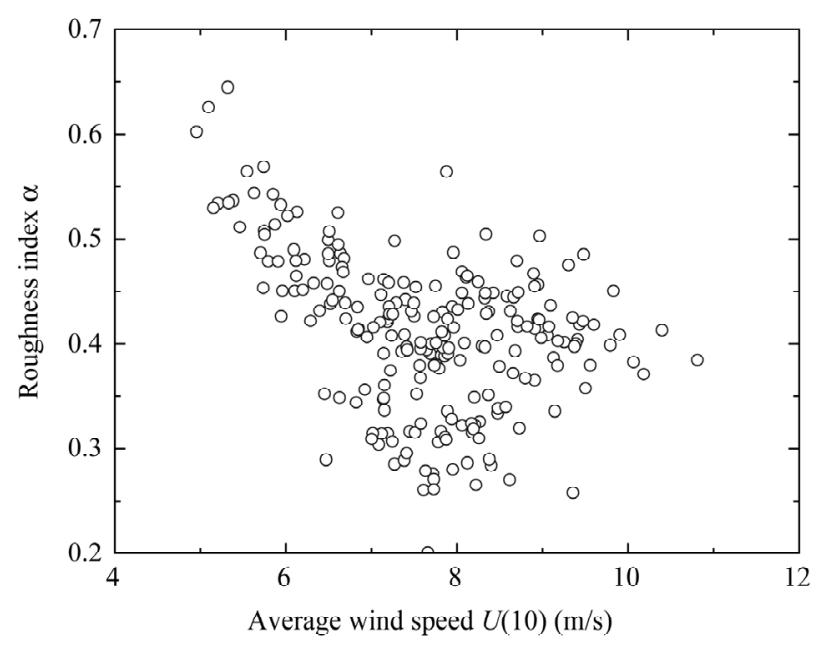

Figure 8. Variation of roughness index with mean wind speed.

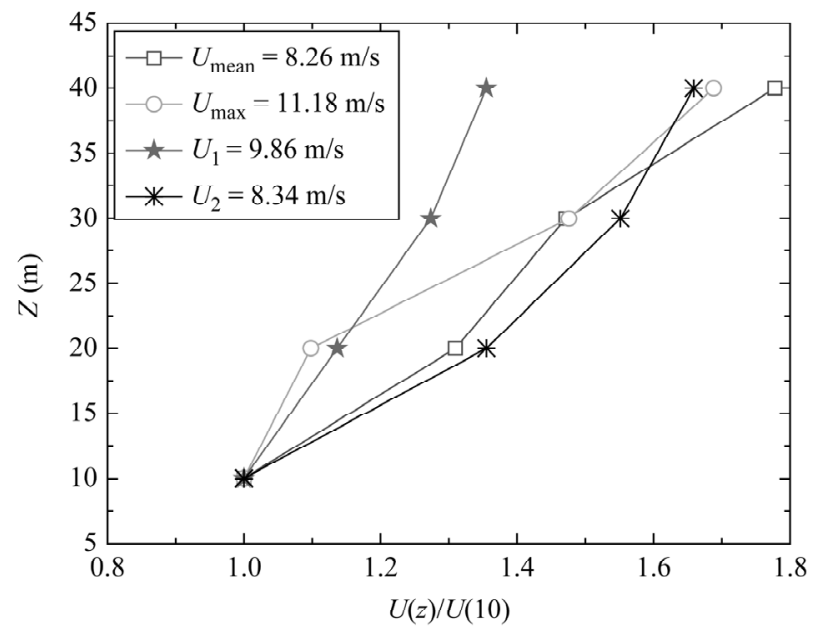

Figure 9. Mean wind speed profiles at different wind speed.

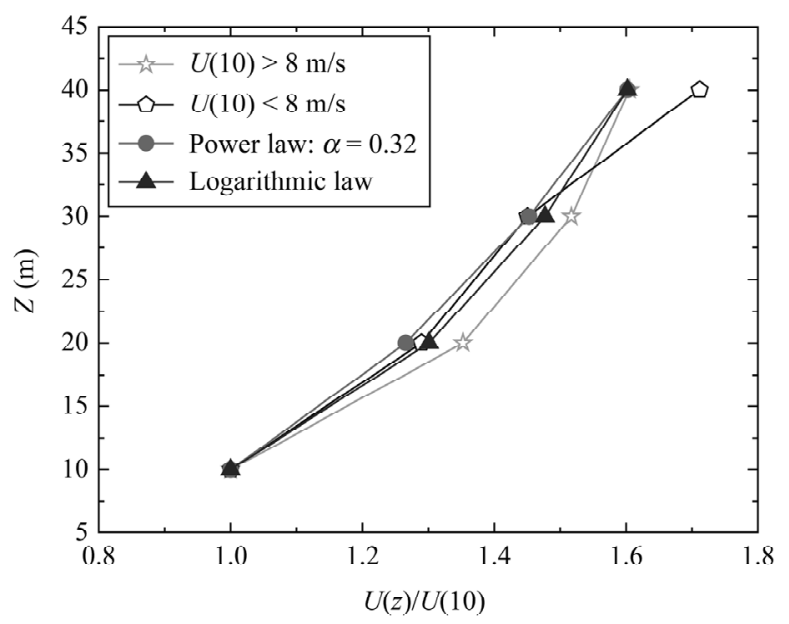

Figure 10. Comparison between measured wind speed profiles and empirical profiles.
Table 1

Expressions for the Turbulence Level in the Specification

\begin{tabular}{|l|c|}
\hline Standards & Empirical Equations \\
\hline ASCE7-10 [24] & $I_{u}=c(33 / z)^{1 / 6}$ \\
\hline AIJ2004 [25] & $I_{u}= \begin{cases}0.1\left(z / z_{g}\right)^{-\alpha-0.05}, \quad z_{b}<z<z_{g} \\
0.1\left(z_{b} / z_{g}\right)^{-\alpha-0.05}, \quad z \leq z_{b}\end{cases}$ \\
\hline Eurocode $[26]$ & $I_{u}= \begin{cases}\frac{1}{\ln \left(z / z_{0}\right)}, & 2 \leq z \leq 200 \\
0.27, & z \leq 2\end{cases}$ \\
\hline
\end{tabular}

Table 2

Turbulence Intensity Profiles Fitting Formula

\begin{tabular}{|l|c|c|}
\hline Wind Direction & Fitting Formula & $R^{2}$ \\
\hline Longitudinal & $I_{u}=0.14(40 / z)^{0.717}$ & 0.95 \\
\hline Horizontal & $I_{v}=0.10(40 / z)^{0.743}$ & 0.96 \\
\hline Vertical & $I_{w}=0.076(40 / z)^{0.686}$ & 0.97 \\
\hline
\end{tabular}

\subsection{Turbulence Intensity Profiles}

The turbulence intensity, especially the longitudinal turbulence intensity, is an important parameter to illustrate the characteristics of the near-ground wind, and the design standards from many countries have given the empirical equations to illustrate the variations of the turbulence intensity with height. Table 1 presents the empirical equations from ASCE7-10 [24], AIJ2004 [25] and Eurocode [26].

To compare the measured turbulence intensity profiles with the empirical profiles from these design standards, the parameters in these empirical equations are assigned as follows: according to the geomorphic type of the surrounding area around the field test site [9]. According to ASCE7-10 [24] and GB50009-2012 [22], $c$ equals to 0.3 in (9); $\alpha$ equals to $0.2, z_{g}$ equals to $450 \mathrm{~m}$ and $z_{b}$ equals to $10 \mathrm{~m}$ in (10); and $z_{0}$ equals to $0.3 \mathrm{~m}$ in (11).

For the use in engineering design, Table 2 presents the fitting formulas of turbulence intensity profiles by the least square method at three directions in the form of $I_{u}=a(40 / z)^{b}$, which is in accordance with the empirical formula by ASCE7-10 [24].

Figure 11 compares the longitudinal turbulence intensity profile with the profiles from design standards of ASCE7-10 [24], AIJ2004 [25] and Eurocode [26]. It is found that the field testing result at $Z=10 \mathrm{~m}$ is close to the result from ASCE7-10 [24], but significantly larger than the results from AIJ2004 [25] and Eurocode [26]. However, the field testing results at $Z=20$ and $30 \mathrm{~m}$ are close to the results from AIJ2004 [25] and Eurocode [26] but obviously smaller than the results from ASCE7-10 [24]. Moreover, the measured result at $Z=40 \mathrm{~m}$ are smaller than the results from these three design standards. Figures 12 and 13 present the measured horizontal and vertical turbulence 


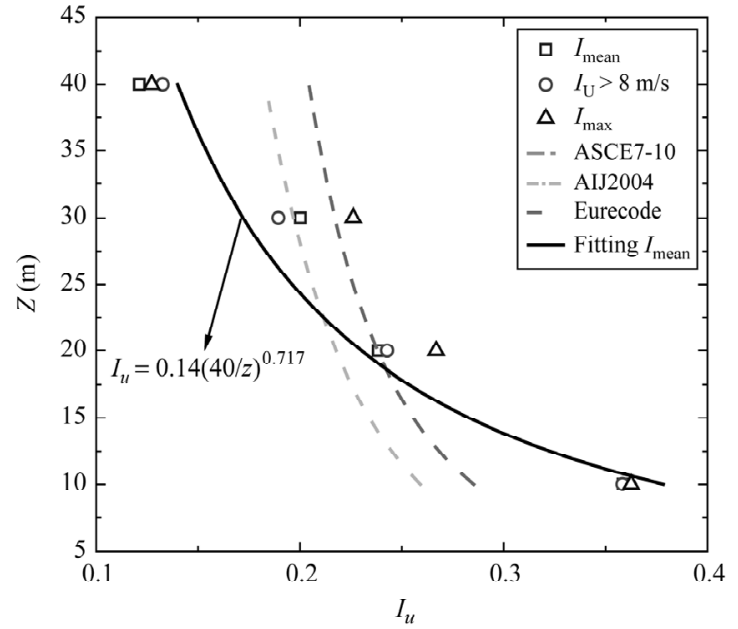

Figure 11. Variation of the longitudinal turbulence intensity with heights.

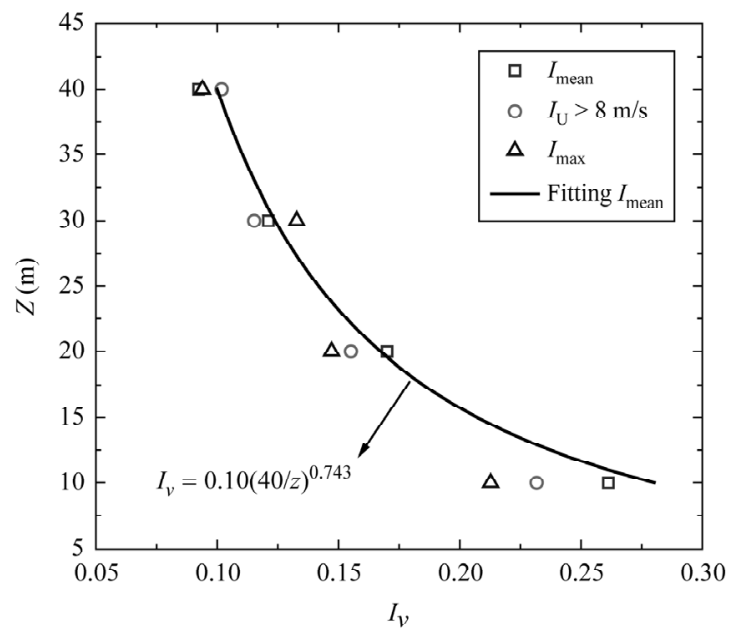

Figure 12. Variation of horizontal turbulence intensity with heights.

intensity profiles, and also give the fitting formulas for these profiles. It is noteworthy that obvious deviations are observed for the measured results at $Z=10 \mathrm{~m}$, and the horizontal and vertical turbulence intensities calculated by the wind speed time series corresponding to the maximum mean wind speed are obviously smaller than the mean values of the horizontal and vertical turbulence intensities.

\subsection{Gust Factor Profiles}

The gust factor is an important parameter to illustrate the wind characteristics. Table 3 represents the fitting formulas for the gust factor profiles at three directions and the fitting formula is $G_{i}=a(z / 10)^{\beta}$. Figure 14 shows the measured gust factors at various directions and heights, and the fitted profiles at three directions are also given in Fig. 14 . As shown in the figure, the fitting profiles of the gust factors are in good agreement with the results from field measurements, which illustrates that the fitting formulas presented in Table 3 can reliably reflect the variations the gust factors with the height.

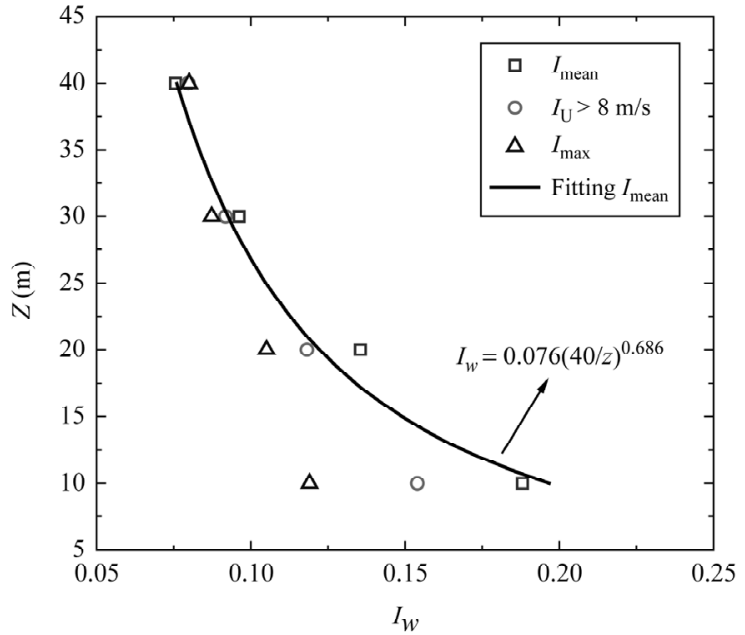

Figure 13. Variation of vertical turbulence intensity with heights.

Table 3

Fitting Formulas of the Gust Factor Profiles at Various Directions

\begin{tabular}{|l|l|c|}
\hline Wind Directions & \multicolumn{1}{|c|}{ Fitting Formula } & $R^{2}$ \\
\hline Longitudinal & $G_{u}=1.68(z / 10)^{-0.204}$ & 0.99 \\
\hline Horizontal & $G_{v}=0.41(z / 10)^{-0.562}$ & 0.98 \\
\hline Vertical & $G_{w}=0.25(z / 10)^{-0.456}$ & 0.97 \\
\hline
\end{tabular}

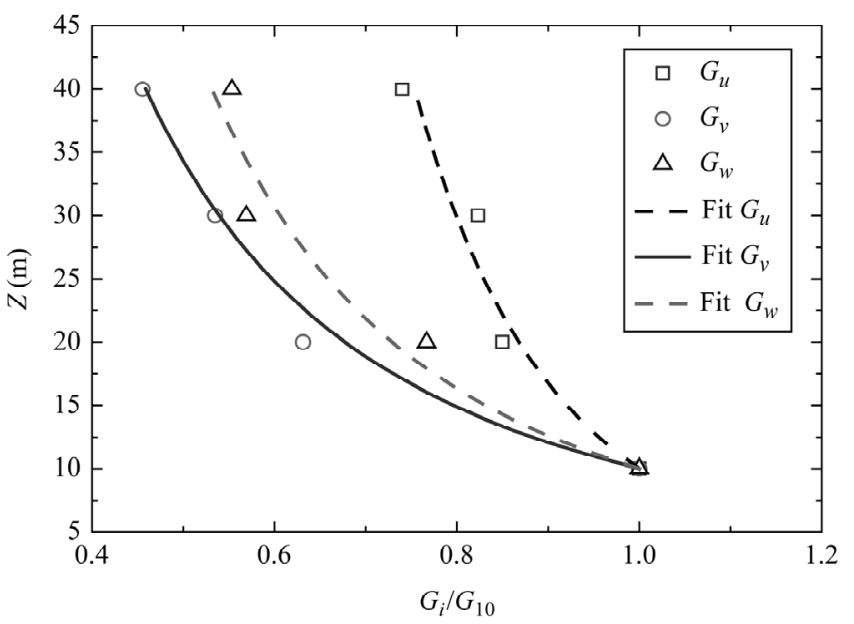

Figure 14. Variations of the gust factors with the height.

\subsection{Turbulence Integral Scale Profiles}

Currently, the design standards from various countries have their own regulations about the variations of the turbulence integral scale with height, but their empirical equations are different and the results of these equations have a relatively large difference. Figure 15 shows the variation of the longitudinal turbulence integral scale with the height from typhoon HAIKUI. The measured results from typhoon Meifa [23] and the simulated profiles of the empirical equations from ASCE7-10 [24] and AIJ2004 [25] 


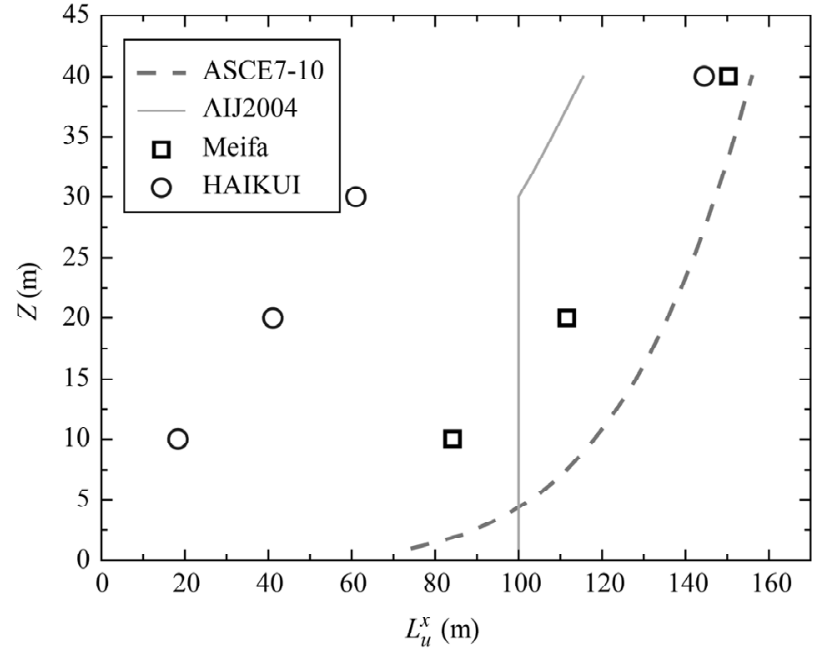

Figure 15. Profiles of longitudinal turbulence integral scales.

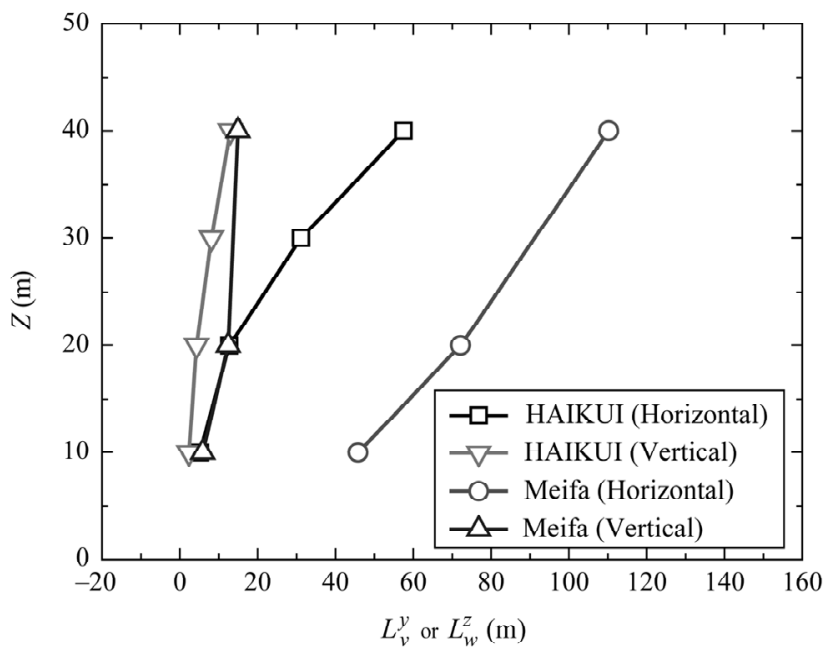

Figure 16. Profiles of horizontal and vertical turbulence integral scales.

are also given in Fig. 16 for comparison. It is found that the longitudinal turbulence integral scales at $Z=10$, 20 and $30 \mathrm{~m}$ from typhoon HAIKUI are obvious smaller than the observed results from the typhoon Meifa and the simulated results from the design standards. At the height of $Z=40 \mathrm{~m}$, the longitudinal turbulence integral scale from typhoon HAIKUI is considerably close to the result from the empirical equation of ASCE7-10 [24].

In addition, Fig. 16 shows the measured profiles of horizontal and vertical turbulence integral scales from typhoon HAIKUI and typhoon Meifa. It is found that the variation tendencies of horizontal turbulence integral scales from typhoon HAIKUI are similar to those from typhoon Meifa, but the values are obviously smaller. However, the profile of vertical turbulence integral scales form typhoon HAIKUI is considerably close to that from typhoon Meifa.

\section{Conclusion}

Field measurements of the near-ground wind characteristics were conducted during typhoon HAIKUI based on a lattice tower in the field test site. The main conclusions are as follows:

(1) The neutral atmospheric stratification $(|z / L| \leq 0.1)$ all occurred in the periods corresponding to the relatively high mean wind speed, and $z / L$ has greater dispersion when the wind speed is relatively low; when the mean wind speed is larger than a certain value, the variation of the $z / L$ with the mean wind speed is small, and tends to stable at 0 .

(2) Variation tendencies of the friction velocity with the mean wind speed at various heights are similar. When wind speed is small, the dispersion of friction velocity is larger, and its variation is not obvious with the mean wind speed, but when the mean wind speed is larger, the friction velocity increases significantly with the mean wind speed.

(3) The measured mean wind speed profile from typhoon HAIKUI is in good agreement with power law and logarithmic law, which is consistent with the observed results from typhoon Meifa [23].

(4) The longitudinal turbulence integral scales at various heights from typhoon HAIKUI are obviously smaller than the observed results from the typhoon Meifa and the simulated results from the design standards; The variation trendencies of the horizontal turbulence integral scales from typhoon HAIKUI are similar to that from typhoon Meifa, but the values are obviously smaller. The profile of vertical turbulence integral scales from typhoon HAIKUI is considerably close to that from typhoon Meifa.

\section{Acknowledgement}

The research described in this paper was financially supported by grants from the National Natural Science Foundation of China (Grant No. 51708074, 51478071, 51408090, $51678452)$, the Key project of foundation and frontier research of Chongqing (Grant No. cstc2017jcyjAX0187, cstc2015jcyjB0014, cstc2015jcyjBX0022), the State Key Laboratory Breeding Base of Mountain Bridge and Tunnel Engineering fund (CQSLBF-Y16-16) and Scientific and Technological Research Program of Chongqing Municipal Education Commission (Grant No. KJ1400333). The authors gratefully acknowledge such financial support.

\section{References}

[1] M. Liu, H. Liao, M. Li, and C. Ma, Field measurements of natural wind characteristics at Xihoumen Bridge, International Conference on Transportation Engineering, 290, 2009, 3681-3686.

[2] J.Y. Fu, J.R. Wu, A. Xu, Q.S. Li, and Y.Q. Xiao, Full-scale measurements of wind effects on Guangzhou West Tower, Engineering Structures, 35, 2012, 120-139.

[3] P. Huang, X. Wang, and M. Gu, Field experiments for wind loads on a low-rise building with adjustable pitch, International Journal of Distributed Sensor Networks, 2012, 2012, 1-10.

[4] H.W. Tieleman, Strong wind observations in the atmospheric surface layer, Journal of Wind Engineering and Industrial Aerodynamics, 96, 2008, 41-77.

[5] X. Wang, B. Chen, D. Sun, and Y. Wu, Study on typhoon characteristic based on bridge health monitoring system, The Scientific World Journal, 2014, 2014, 1-11. 
[6] J.Y. Fu, Q.S. Li, J.R. Wu, Y.Q. Xiao, and L.L. Song, Field measurements of boundary layer wind characteristics and wind-induced responses of super-tall buildings, Journal of Wind Engineering and Industrial Aerodynamics, 96, 2008, 1332-1358.

[7] Q.S. Li, L.H. Zhi, and F. Hu, Boundary layer wind structure from observations on a $325 \mathrm{~m}$ tower, Journal of Wind Engineering and Industrial Aerodynamics, 98, 2010, 818-832.

[8] B. Wang, F. Hu, and X.L. Cheng, Wind gust and turbulence statistics of typhoons in South China, Acta Meteorologica Sinica, 25, 2011, 113-127.

[9] P. Huang, X. Wang, and M. Gu, Study on near-ground wind characteristics of a strong typhoon: Wind speed, turbulence intensities, gust factors and peak factors, Disaster Advances, $6,2013,3-18$.

[10] K.T. Tse, S.W. Li, C.Q. Lin, and P.W. Chan, Wind characteristics observed in the vicinity of tropical cyclones: An investigation of the gradient balance and super-gradient flow, Wind and Structures, 19(3), 2014, 249-270.

[11] K.T. Tse, S.W. Li, and J.C.H. Fung, A comparative study of typhoon wind profiles derived from field measurements, mesoscale numerical simulations, and wind tunnel physical modeling, Journal of Wind Engineering and Industrial Aerodynamics, 131, 2014, 46-58.

[12] S.W. Li, K.T. Tse, A.U. Weerasuriya, and P.W. Chan, Estimation of turbulence intensities under strong wind conditions via turbulent kinetic energy dissipation rates, Journal of Wind Engineering and Industrial Aerodynamics, 131, 2014, 1-11.

[13] B.H. Xia, Z.S. Chen, T.L. Li, Y.D. Yang, Y. Li, and L. Mei, Construction control of a long span cable-stayed rail transit bridge, International Journal of Robotics and Automation, 32, 2017, 274-282.

[14] Z.S. Chen, J.T. Zhou, G. Hu, Y. Li, H. Ma, and G.W. Yao, A novel movable scaffolding system (MSS) for a long-span curved girder bridge, International Journal of Robotics and Automation, 2017.

[15] A.G. Davenport, Rationale for determining design wind velocities, Journal of the Structural Division, 86, 1960, 39-68.

[16] E. Simiu and R.H. Scanlan, Wind effects on structuresfundamentals and applications to design (New York: John Wiley and Sons, 1996), 39-40.

[17] G.J. Flay and D.C. Stevenson, Integral length scales in strong winds below 20m, Journal of Wind Engineering and Industrial Aerodynamics, 28, 1988, 21-30.

[18] R.K. Garg, J.X. Lou, and M. Kasperski, Some features of modeling spectral characteristics of flow in boundary layer wind tunnels, Journal of Wind Engineering and Industrial Aerodynamics, 72, 1997, 1-12.

[19] D.A. Reed and R.H. Scanlan, Autoregressive representation of longitudinal, lateral, and vertical turbulence spectra, Journal of Wind Engineering and Industrial Aerodynamics, 17, 1984, 199-214.

[20] N. Kato, T. Ohkuma, J.R. Kim, H. Marukawa, and Y. Niihori, Full scale measurements of wind velocity in two urban areas using an ultrasonic anemometer, Journal of Wind Engineering and Industrial Aerodynamics, 41, 1992, 67-78.

[21] S. Liu, F. Hu, and H. Liu, Turbulence length scales, dissipation rates and structure parameters above the forest canopy, Acta Scientiarum Naturalium-Universitatis Pekinensis, 39, 2003, 73-82.

[22] GB50009-2012, Load code for the design of building structures (China Architecture and Building Press, Beijing, 2012), 30-35.

[23] X. Wang, P. Huang, and M. Gu, Variation of wind profiles near ground during typhoon "Muifa", Journal of Tongji University: Natural Science Edition, 41, 2013, 1165-1171 (in Chinese).

[24] ASCE7-10, Minimum design loads for buildings and other structures, American Society of Civil Engineers, New York, 2010.

[25] AIJ2004, Recommendations for loads on buildings, Architectural Institute of Japan, Tokyo, 2004.

[26] Structural Eurocodes, Eurocode 1: Actions on structuresGeneral actions-Part 1-4: Wind actions. Technical Committee CEN/TC250, British Standards Institution, London, 2004.

\section{Biographies}
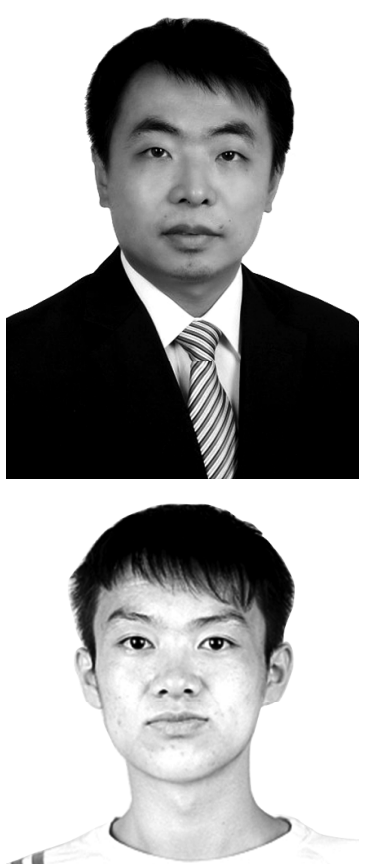

Huaqiang $L i$ pursuing master, Chongqing Jiaotong University, mainly engaged in structural wind resistance research
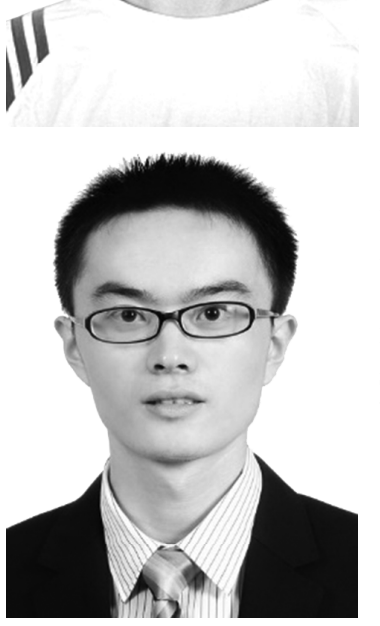

Zeng-shun Chen is a Ph.D. candidate and majoring in Civil Engineering of the Hong Kong University of Science and Technology. His research interests are structural wind engineering and bridge engineering.

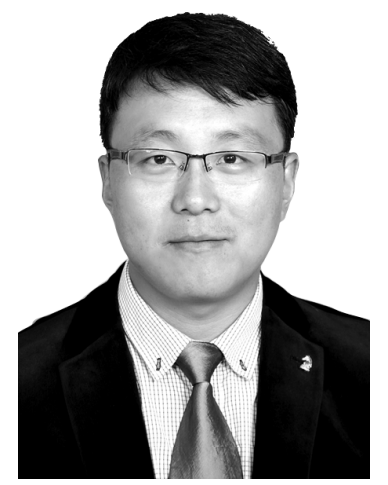

Hua-ming Dong master's degree, mainly engaged in bridge construction and bridge state control optimization.

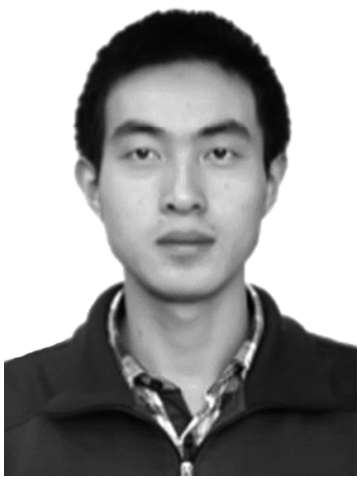

Yangjian Xiao is a Ph.D. candidate and majoring in bridge engineering of college of civil engineering of Chongqing Jiaotong University. His research interests are bridge inspection and evaluation. 